\title{
Iron status and associations with physical performance during basic combat training in female New Zealand Army recruits
}

\author{
Nicola M. Martin ${ }^{1,2} \dagger$, Cathryn A. Conlon ${ }^{2}$, Rebecca J. M. Smeele ${ }^{3} \dagger$, Owen A. R. Mugridge ${ }^{2}$, \\ Pamela R. von Hurst ${ }^{2}$, James P. McClung ${ }^{4} \ddagger$ and Kathryn L. Beck ${ }^{2 *}$ \\ ${ }^{1}$ New Zealand Army, New Zealand Defence Force, Trentham Military Camp, Upper Hutt 5019, New Zealand \\ ${ }^{2}$ School of Sport, Exercise and Nutrition, College of Health, Massey University, North Shore, Auckland 0745, New Zealand \\ ${ }^{3}$ Royal New Zealand Naval Reserve, New Zealand Defence Force, Christchurch 8013, New Zealand \\ ${ }^{4}$ Military Nutrition Division, US Army Research Institute of Environmental Medicine, Natick, MA O1760, USA
}

(Submitted 20 August 2018 - Final revision received 7 January 2019 - Accepted 16 January 2019 - First published online 13 March 2019)

\section{Abstract}

Decreases in Fe status have been reported in military women during initial training periods of 8-10 weeks. The present study aimed to characterise Fe status and associations with physical performance in female New Zealand Army recruits during a 16-week basic combat training (BCT) course. Fe status indicators - Hb, serum ferritin (sFer), soluble transferrin receptor (sTfR), transferrin saturation (TS) and erythrocyte distribution width (RDW) - were assessed at the beginning (baseline) and end of BCT in seventy-six volunteers without Fedeficiency non-anaemia (sFer $<12 \mu \mathrm{g} / \mathrm{l} ; \mathrm{Hb} \geq 120 \mathrm{~g} / \mathrm{l}$ ) or Fe-deficiency anaemia (sFer $<12 \mu \mathrm{g} / \mathrm{l} ; \mathrm{Hb}<120 \mathrm{~g} / \mathrm{l}$ ) at baseline or a C-reactive protein $>10 \mathrm{mg} / \mathrm{l}$ at baseline or end. A timed $2.4 \mathrm{~km}$ run followed by maximum press-ups were performed at baseline and midpoint (week 8) to assess physical performance. Changes in Fe status were investigated using paired $t$ tests and associations between Fe status and physical performance evaluated using Pearson correlation coefficients. sFer (56.6 (sD 33.7) v. 38.4 (sD 23.8) $\mu \mathrm{g} / \mathrm{l}$ ) and TS (38.8 (sD 13.9) $v$. 34.4 (sD $11.5) \%$ ) decreased $(P<0.001$ and $P=0.014$, respectively), while sTfR $(1.21$ (sD 0.27$) v .1 .39$ (sD 0.35$) \mathrm{mg} / \mathrm{l})$ and RDW (12.8 (sD 0.6$) v .13 .2(\mathrm{sD}$ $0.7) \%$ ) increased $(P<0.001)$ from baseline to end. Hb (140.6 (sD 7.5) v. 142.9 (sD 7.9) g/l) increased $(P=0.009)$ during BCT. At end, sTfR was positively $(r 0.29, P=0.012)$ and TS inversely associated $(r-0.32, P=0.005)$ with midpoint run time. There were no significant correlations between Fe status and press-ups. Storage and functional Fe parameters indicated a decline in Fe status in female recruits during BCT. Correlations between tissue-Fe indicators and run times suggest impaired aerobic fitness. Optimal Fe status appears paramount for enabling success in female recruits during military training.

Key words: Iron deficiency: Aerobic fitness: Military women: Serum ferritin: Soluble transferrin receptor

Fe is important for physically active women, including military women, due to its essential role in maintaining physical and neuropsychological performance ${ }^{(1)}$. Premenopausal women are particularly at risk of poor Fe status due to inadequate dietary intake of $\mathrm{Fe}$ and menstrual blood loss ${ }^{(2,3)}$. Exercise may further contribute to negative Fe balance ${ }^{(4,5)}$.

The prevalence of both Fe-deficiency non-anaemia (IDNA) and Fe-deficiency anaemia (IDA) is widely reported to be higher in physically active women and competitive athletes when compared to the general population ${ }^{(6-10)}$. Following initial military training, the prevalence of IDNA has been shown to increase in female army recruits ${ }^{(11,12)}$. The effect of IDA on reduced aerobic performance is well documented ${ }^{(13-15)}$. Although the effect of IDNA is not well described, it has been reported to impair aerobic adaptation and endurance capacity in women ${ }^{(16-18)}$.

Whilst all military personnel are exposed to cognitive and physical challenges, the changes in Fe status that women typically incur during intensive periods of physical exertion could impact their response to these challenges ${ }^{(11)}$. Basic combat training (BCT) provides a unique setting to investigate Fe status. Not only do all recruits perform the same form and

\footnotetext{
Abbreviations: BCT, basic combat training; CRP, C-reactive protein; IDA, iron-deficiency anaemia; IDNA, iron-deficiency non-anaemia; sFer, serum ferritin; sTfR, soluble transferrin receptor; TS, transferrin saturation.

* Corresponding author: Dr K. L. Beck, email k.1.beck@massey.ac.nz

$\dagger$ The views and opinions expressed in this article are those of the authors and do not necessarily reflect the official views or opinions of the New Zealand Defence Force.

\$ The views, opinions and/or findings in this report are those of the authors and should not be construed as official Department of the Army or Department of Defense position, policy or decision unless so designated by other official designation.
} 
intensity of physical training, but the environment is controlled for variables such as sleep, dietary intake, sedentary behaviour, altitude and access to health care ${ }^{(19)}$. Previous studies investigating the $\mathrm{Fe}$ status of female recruits have been limited to 10 weeks and measured running performance as a marker of physical fitness during training ${ }^{(11,12,18,20)}$. As these studies were all based in the USA, it is important to confirm these findings in other populations that may differ due to age, ethnicity, dietary intake, physical fitness and variations in the military training conducted.

The New Zealand Defence Force (NZDF) comprises 17\% women in the Regular Force, with a goal to achieve $25 \%$ by $2025^{(21)}$. This is consistent with a global drive from international defence forces to enhance roles and opportunities for women in the military. Identifying the effects of diminished Fe status on physical performance, particularly with more subtle changes in Fe status that fall outside of the clinical diagnostic parameters, has been considered as an important area for future research $^{(1,22)}$. Therefore, the aim of this study was to characterise Fe status in female New Zealand Army recruits during BCT and associations with operationally relevant indicators of physical performance.

\section{Methods}

\section{Participants}

All female recruits who enlisted in the New Zealand Army from February 2014 to March 2016 were eligible and invited to participate in this longitudinal cohort study. The study was conducted at Waiouru Military Camp located at $792 \mathrm{~m}$ above sea level in the central North Island of New Zealand. It is the only location for the 16-week BCT course for all New Zealand Army recruits. This study was conducted according to the guidelines laid down in the Declaration of Helsinki, and all procedures involving human subjects were approved by the Massey University Human Ethics Committee: Southern A (Application - 13/ 85). Investigators also adhered to Defence Force Order 3, which prescribes the NZDF policy relating to conduct and approval of personnel research. All participants provided informed and voluntary consent.

\section{Study procedures}

Anthropometric measurements and blood collection for $\mathrm{Fe}$ status indicators were conducted in a fasted state between 06.00 and 07.30 hours during week 1 (baseline) and week 16 (end of BCT) for all participants, with instructions not to consume water before analysis. No exercise was performed for at least $8 \mathrm{~h}$ before these assessments. Demographic data (age and ethnicity) were collected at baseline using a questionnaire. Physical performance was assessed at baseline and during week 8 (mid). A timed $2.4 \mathrm{~km}$ run was conducted as a measure of aerobic fitness followed by maximum press-ups as a measure of muscular endurance of the upper body.

\section{Basic combat training}

BCT involves aerobic activities such as prolonged standing and marching in formation; tactical marching with load carriage; distance running and obstacle courses; as well as muscle strength training that includes own-body weight exercises, lifting, load carriage and climbing. Organised physical training sessions are conducted three to four times per week for a period of approximately $1 \mathrm{~h}$. Other military activities involve the fundamentals of weapons training, first aid, navigation, classroom instruction and military field training. The 16-week course is residential and recruits live in shared barrack accommodation. Recruits consume three meals per $\mathrm{d}$ from a range of dining options, including self-selected meals in a dining hall facility to bag lunches and operational ration packs. Additional snacks are provided and recruits are not permitted to consume any dietary supplements unless prescribed by a medical doctor. All menus for dining halls and packed rations meet the Nutrient Reference Values for Australia and New Zealand ${ }^{(23)}$.

\section{Ethnicity}

This study used the concept of total response ethnicity ${ }^{(24)}$ which classifies participants in all ethnic groups they identify with. Therefore, participants may appear in more than one ethnic group and the sum of the ethnic groups may be greater than the number of participants.

\section{Anthropometrics}

Participants were asked to wear light shorts and a T-shirt and remove any metal such as jewellery. Anthropometric measures were determined at baseline and end, with the exception of height, which was measured at baseline only using a SECA 213 Portable Stadiometer (German Healthcare Export Group). Height was measured by a trained anthropometrist using the International Society for the Advancement of Kinanthropometry protocols ${ }^{(25)}$. Body mass was measured via bioelectrical impedance analysis using the InBody230 (Biospace Co. Ltd). BMI was calculated as mass $(\mathrm{kg}) /$ height $(\mathrm{m})^{2}$.

\section{Blood sampling and analysis}

A venepuncture blood sample of $18 \mathrm{ml}$ in total was collected at both baseline and end. $\mathrm{Hb}$ and erythrocyte distribution width (RDW) were analysed using a Sysmex XT-2000i automated haematology analyser (Sysmex Corporation). The Cobas ${ }^{\circledR} 6000$ (Roche Diagnostics) was used to analyse serum ferritin (sFer) (electrochemiluminescence immunoassay, e601); serum $\mathrm{Fe}$ (sFe) (two-point end method with a colourimetric assay, c501); and transferrin ( $\mathrm{Tf}$ ) and C-reactive protein (CRP) (both using the two-point end method with an immunoturbidimetric assay, c501). For sFer, at control levels of $1 \cdot 1,12 \cdot 3,20 \cdot 5$ and $392 \mu \mathrm{g} / 1$ the within-assay $\mathrm{CV}$ were $12 \cdot 4,3 \cdot 8,4 \cdot 1$ and $2 \cdot 1 \%$, respectively, and the between-assay $\mathrm{CV}$ were $23 \cdot 4,6 \cdot 4,8 \cdot 1$ and $4 \cdot 3 \%$, respectively. For $\mathrm{sFe}$ at 11.3 and $54.5 \mu \mathrm{mol} / \mathrm{l}$, the within-assay CV were 1.3 and $0.8 \%$, respectively, whilst the between-assay $\mathrm{CV}$ at 11.8 and $55.1 \mu \mathrm{mol} / \mathrm{l}$ were 1.8 and $1.3 \%$. For Tf at 1.27 and 
$2.63 \mathrm{~g} / \mathrm{l}$, the within-assay CV were 1.2 and $1.5 \%$, respectively; whilst the between-assay $\mathrm{CV}$ at 2.14 and $2.96 \mathrm{~g} / 1$ were 0.06 and $0.08 \%$. Total Fe binding capacity (TIBC) was calculated by multiplying Tf by $22 \cdot 8$. Transferrin saturation (TS) was calculated by dividing sFe by TIBC and multiplying by 100 . Soluble transferrin receptor (sTfR) was analysed using a Siemens $\mathrm{BN}^{\mathrm{TM}}$ II System (Siemens Healthcare Diagnostics Inc.) using N-point nephelometry with monoclonal antibodies. At control levels of 0.71 and $1.47 \mathrm{mg} / \mathrm{l}$ for sTfR, the within-assay CV were 1.4 and $1.5 \%$, respectively, and the between-assay CV were 4.2 and $3 \cdot 8 \%$, respectively. For the Siemens $\mathrm{BN}^{\mathrm{TM}}$ II System, Fe deficiency for sTfR is indicated when values exceed $1.76 \mathrm{mg} / \mathrm{l}$.

The sTfR was analysed at Canterbury Health Laboratories, while all other biomarkers were analysed at Medlab Whanganui. All assays were run with the appropriate standards and both internal and external quality control processes. In the absence of an external QC programme for sTfR, samples were exchanged with another New Zealand laboratory to analyse precision. All laboratories are accredited with International Accreditation New Zealand.

Participants were excluded if they had IDNA (sFer $<12 \mu \mathrm{g} / \mathrm{l}$ and $\mathrm{Hb} \geq 120 \mathrm{~g} / \mathrm{l})$ or IDA (sFer $<12 \mu \mathrm{g} / \mathrm{l}$ and $\mathrm{Hb}<120 \mathrm{~g} / \mathrm{l}$ ) at baseline; CRP $>10 \mathrm{mg} / \mathrm{l}$ at baseline or end; or if they were prescribed Fe supplementation during the study period. Participants who had received Fe supplementation before the study period, but not during, were included in the analysis.

\section{Physical performance}

A timed $2.4 \mathrm{~km}$ (1.5-mile) run, followed by maximum press-ups and curl-ups are the three components of the base physical fitness standard for New Zealand Army personnel. All recruits must qualify at the minimum standard during BCT. For women aged 16-24 years, this is completion of the run in $12 \mathrm{~min}$ and $20 \mathrm{~s}$, fourteen press-ups and fifty curl-ups. The run time and number of press-ups were analysed at baseline (week 1) and the midpoint (week 8).

\section{Statistical analysis}

Statistical analysis was performed using IBM SPSS Statistics for Windows, version 24.0 (IBM Corp). The Kolmogorov-Smirnov and Shapiro-Wilk tests and box plots were used to assess the data for normality. Descriptive statistics are presented as either mean values and standard deviations or median values with 25th and 75th percentiles. Changes in Fe status indicators and anthropometric measures were investigated using paired $t$ tests. Independent $t$ tests investigated any difference in Fe status indicators or anthropometric measures between those participants that completed BCT and participants that did not. Associations between Fe status indicators and physical performance were evaluated using Pearson correlation coefficients. A $P$ value $<0.05$ was considered statistically significant.

As the sample size was determined by the feasibility of recruitment, effect sizes are reported as $r$ and classified as small $=0.1$ (accounts for $1 \%$ of total variance), medium $=0.3$ (accounts for $9 \%$ of total variance) and large $=0.5$ (accounts for $25 \%$ of total variance). Effect sizes are calculated as $r=\sqrt{ } t^{2}$ / $\left(t^{2}+\mathrm{df}\right)$, where $t$ is the test statistic ${ }^{(26)}$.

\section{Results}

Of the 108 female recruits invited to take part in this study, 106 volunteered to participate. Data for sixteen were excluded: seven had IDNA and three had IDA at baseline; and four participants at baseline and two at the end had a CRP $>10 \mathrm{mg} / \mathrm{l}$. A further fourteen participants did not complete BCT: ten were removed from their initial course due to lower limb injuries, including four stress fractures; one due to mental health; and three participants self-withdrew from BCT. Table 1 shows age, ethnicity and anthropometric measures for the remaining seventy-six participants. There was no significant difference in body mass, BMI or Fe status indicators at baseline between those participants that completed BCT and the fourteen participants that did not.

Nearly all Fe indicators suggest a decline in Fe status at the end of BCT (Table 2). sFer and TS decreased (effect size, $r 0.67$, $P<0.001$ and $r 0 \cdot 28, P=0 \cdot 014$, respectively), while sTfR $(r 0.63)$ and RDW $(r$ 0.62) increased $(P<0.001)$, all indicating reduced Fe status. $\mathrm{Hb}$ increased $(r 0.30, P=0.009)$ during BCT. The mean sFer was reduced by $32 \cdot 2 \%$ from baseline, whilst the mean STfR and TS changed by 14.9 and $11.3 \%$, respectively, over the same 16-week period. At the end of BCT, $11.8 \%$ of

Table 1. Characteristics of study participants at baseline and end of basic combat training (Mean values and standard deviations; medians, 25th and 75th percentiles)

\begin{tabular}{|c|c|c|c|c|c|}
\hline & \multicolumn{2}{|c|}{ Baseline ( $n 76)$} & \multicolumn{2}{|c|}{ End $(n 76)$} & \multirow[b]{2}{*}{$P^{\star}$} \\
\hline & Mean & $\mathrm{SD}$ & Mean & SD & \\
\hline \multicolumn{6}{|l|}{ Ethnicity $(n)$} \\
\hline European & \multicolumn{2}{|c|}{58} & & & \\
\hline Māori & \multicolumn{2}{|c|}{22} & & & \\
\hline Pacific & \multicolumn{2}{|c|}{16} & & & \\
\hline \multicolumn{6}{|l|}{ Age (years) } \\
\hline Median & \multirow{2}{*}{\multicolumn{2}{|c|}{$\begin{array}{c}18 \\
18,19\end{array}$}} & & & \\
\hline 25th, 75 th percentiles & & & & & \\
\hline Height $(\mathrm{cm})$ & $165 \cdot 1$ & 5.5 & & & \\
\hline Weight (kg) & 65.8 & 9.5 & 65.5 & 7.4 & 0.568 \\
\hline BMI $\left(\mathrm{kg} / \mathrm{m}^{2}\right)$ & 24.1 & 2.9 & 24.0 & 1.9 & 0.583 \\
\hline
\end{tabular}

* $P$ value determined using paired $t$ tests. 
Table 2. Changes in iron status indicators during basic combat training (Mean values and standard deviations)

\begin{tabular}{|c|c|c|c|c|c|}
\hline & \multicolumn{2}{|c|}{ Baseline ( $n$ 76) } & \multicolumn{2}{|c|}{ End $(n 76)$} & \multirow[b]{2}{*}{$P^{\star}$} \\
\hline & Mean & SD & Mean & SD & \\
\hline $\mathrm{Hb}(\mathrm{g} / \mathrm{l})$ & 140.6 & 7.5 & 142.9 & 7.9 & 0.009 \\
\hline sFer $(\mu \mathrm{g} / \mathrm{l})$ & 56.6 & $33 \cdot 7$ & 38.4 & $23 \cdot 8$ & $<0.001$ \\
\hline $\operatorname{sTfR}(\mathrm{mg} / \mathrm{l}) \dagger$ & 1.21 & 0.27 & 1.39 & 0.35 & $<0.001$ \\
\hline TS (\%) & 38.8 & 13.9 & $34 \cdot 4$ & 11.5 & 0.014 \\
\hline RDW (\%) & $12 \cdot 8$ & 0.6 & $13 \cdot 2$ & 0.7 & $<0.001$ \\
\hline
\end{tabular}

sFer, serum ferritin; sTfR, serum transferrin receptor; TS, transferrin saturation; RDW, erythrocyte distribution width.

${ }^{*} P$ value determined using paired $t$ tests.

† sTfR is typically reported to two decimal points for clinical significance.

participants had an sTfR level greater than the clinical cut-off of $1.76 \mathrm{mg} / \mathrm{l}$ compared with $3.9 \%$ at baseline. Nine percent participants with normal Fe status at baseline had IDNA at the end and a further $3 \%$ had IDA.

Due to injuries, only sixty-nine of seventy-six participants completed the $2.4 \mathrm{~km}$ run and press-ups at baseline. All seventy-six completed the $2.4 \mathrm{~km}$ run and press-ups at the midpoint. The range for run times was $10 \mathrm{~min} 0 \mathrm{~s}$ to $14 \mathrm{~min} 18 \mathrm{~s}$ at baseline and $9 \mathrm{~min} 20 \mathrm{~s}$ to $13 \mathrm{~min} 11 \mathrm{~s}$ at the midpoint. Pearson's correlation coefficient was used to analyse the association between Fe status indicators and physical performance during BCT. At the end point, sTfR was positively associated $(r$ $0 \cdot 29, P=0 \cdot 012)$ and TS inversely associated $(r-0 \cdot 32, P=0 \cdot 005)$ with the $2.4 \mathrm{~km}$ run time at the midpoint. There was no significant correlation between the Fe status indicators and the number of press-ups performed.

\section{Discussion}

This is the first study to investigate the Fe status of women in the New Zealand Army and associations with operationally relevant functional outcomes. Fe indicators (excluding $\mathrm{Hb}$ ) suggested a decline in Fe status during BCT for female recruits. Secondary findings were that reduced Fe status, as indicated by increased sTfR and decreased TS, were associated with impaired running performance; and there was no significant correlation between Fe indicators and press-ups. These findings are important in the military training environment because of the associations between aerobic fitness and injury risk $^{(19)}$ and the ability to carry out physically demanding occupational tasks ${ }^{(27)}$. Female soldiers will continue to be exposed to strenuous tasks during their careers, including the period immediately after BCT when soldiers will complete an advanced training course.

The significant changes in Fe indicators observed during BCT reflect those found in previous studies of women undergoing initial military training ${ }^{(11,12,18,20)}$. The $32 \%$ reduction in sFer from baseline is similar to the $34 \%$ decrease in the US Army female recruits during 8 weeks of $\mathrm{BCT}^{(18)}$ and the $33 \%$ decrease observed in elite female weight-bearing athletes during the first 4-6 weeks of a training season ${ }^{(28)}$. sFer was the largest biomarker change during the present study and may indicate that Fe stores are most sensitive to declines in Fe status due to military training. This finding supports the importance of sFer as a biomarker for the early identification of Fe deficiency, as despite the longer duration of the present study, decreases in sFer of a greater magnitude were not seen.

The significant elevation in $\mathrm{Hb}$ observed in the present study has been reported previously for female recruits following BCT over 8-9 weeks $^{(12,18,20)}$. Increased $\mathrm{Hb}$ levels coupled with reduced sFer levels may indicate the mobilisation of Fe away from storage proteins (ferritin) for the production of erythrocytes and maintenance of oxygen delivery ${ }^{(12)}$. Alongside instructions not to consume water before blood sampling, the use of a dynamic panel of Fe biomarkers provides a further control for hydration state, indicating true biological changes in Fe status. The present study did not extend beyond the 120- $\mathrm{d}$ lifespan of erythrocytes to help understand what may happen to the Fe status of female recruits over that duration. This is of interest, as upon completion of BCT, soldiers will likely proceed immediately on to advanced training.

Significant changes in sTfR and TS from baseline to end indicated a reduction in $\mathrm{Fe}$ status in the present study and were the only indicators associated with impaired aerobic fitness. Our finding that STfR was correlated with $2.4 \mathrm{~km}$ running performance at the midpoint supports the findings of McClung et al. ${ }^{(18)}$ who demonstrated that the change in STfR during BCT was correlated with $3.2 \mathrm{~km}$ run time. Work in previously untrained premenopausal women also identified a relationship between sTfR and aerobic performance during time trials on a cycle ergometer $^{(16,17,29)}$. Decreases in sTfR following Fe supplementation were significantly associated with improvements in relative maximal aerobic capacity $\left(\mathrm{VO}_{2 \max }\right)^{(16)}$ and $\% \mathrm{VO}_{2 \max }$ used during work $^{(17,29)}$. TS was correlated with run time at the midpoint in the present study. Brownlie et al. ${ }^{(16)}$ also found an association with TS and aerobic capacity, particularly in subjects who had elevated sTfR levels. Brownlie et $a l^{(16)}$ and Hinton et $a l^{(29)}$ demonstrated that improvements in Fe status following supplementation can increase oxidative capacity at the tissue level to improve maximal work capacity and endurance performance, at least when the sTfR levels approach the cut-off values used for Fe deficiency. These findings suggest that indicators of tissue-Fe deficiency, such as sTfR and TS, are more closely associated with aerobic fitness, compared with sFer (stored Fe). Brownlie et $a l .{ }^{(17)}$ proposed that tissue-Fe deficiency impairs the ability of mitochondria and myoglobin to adapt in response to aerobic training. STfR and TS can therefore be used to distinguish between $\mathrm{Fe}$ depletion and functional Fe deficiency, which impairs the adaptation in endurance capacity as a result of 
aerobic training. In the present study, reduced tissue-Fe status likely impaired the ability of female recruits to carry out typical military tasks, which are often aerobically demanding ${ }^{(27)}$.

The association between poor Fe status and reduced aerobic performance is typically strongest in those with IDA $^{(13-15)}$; whilst IDNA has been reported to impair aerobic adaptation and endurance capacity in women ${ }^{(16-18)}$. After excluding participants with IDNA and IDA at baseline (but not at the end), the present study indicated a linear relationship between declining Fe status and slower run times in physically active women who mostly had clinically normal Fe status.

Run times are a validated measure of aerobic fitness ${ }^{(27)}$, and slower run times indicate lower aerobic fitness, which has been strongly and consistently associated with higher risk of injuries among male and female recruits in both the US and British Armies ${ }^{(19,30-33)}$. Press-ups are a measure of muscular endurance. Whilst a recent systematic review demonstrated a strong correlation between press-ups and performance of common military tasks, press-ups have not been shown to be as strongly or as consistently associated with risk of injury as aerobic fitness measures ${ }^{(34)}$. As hypothesised in the present study, there was no significant correlation between Fe status indicators and the number of press-ups performed. Press-ups predominantly use the anaerobic energy system, and Peeling et al. ${ }^{(4)}$ suggested that anaerobic-based tests are not sensitive or specific enough to demonstrate the effects of Fe status on physical performance.

Of the 100 female recruits who volunteered to participate in the present study and did not have elevated CRP levels, $7 \%$ had IDNA and 3\% had IDA at baseline. This is lower than the 10.6 and $5.2 \%$ for IDNA and IDA, respectively, in females aged 15-18 years living in New Zealand ${ }^{(35)}$. The prevalence of $\mathrm{Fe}$ deficiency at baseline was also lower than that reported previously in female army recruits in the $\operatorname{USA}^{(11,12,20)}$ and Israel $^{(36,37)}$. Whilst all studies used a sFer cut-off of $12 \mu \mathrm{g} / \mathrm{l}$, the US-based studies used a three-variable model to identify participants with IDNA or IDA. Participants were categorised with Fe deficiency if they presented with at least two of the following three abnormal Fe status indicators: sFer $<12 \mu \mathrm{g} / \mathrm{l}$, TS $<16 \%$ or RDW $>15 \%$. The participants were then classified as IDNA if $\mathrm{Hb} \geq 120 \mathrm{~g} / \mathrm{l}$ or IDA if $\mathrm{Hb}<120 \mathrm{~g} / \mathrm{l}^{(11,12,18,20)}$. Although the present study used sFer as a single indicator for IDNA, all subjects with a CRP $>10 \mathrm{mg} / \mathrm{l}$ at baseline or end were excluded from the analysis ${ }^{(38)}$ to mitigate against sFer elevations in response to inflammation or infection ${ }^{(39)}$. Whilst not reported, all participants with IDNA and IDA at the end of BCT had at least two and four diminished Fe biomarkers, respectively.

A number of factors are likely to contribute to the decrements in Fe status demonstrated in the present study. Increased Fe demand may result from higher rates of erythrocyte production and whole-body Fe turnover during periods of more intense physical activity ${ }^{(40)}$. The development of lean body mass is a potentially $\mathrm{Fe}$ demanding process that may contribute to depletion of Fe status. There was an $8.9 \%$ increase $(P<0.001)$ and $22.5 \%$ decrease $(P<0.001)$ in skeletal muscle mass and fat mass, respectively, from baseline to end. These body composition changes are in the expected direction following BCT. Increased Fe losses, over and above menstrual bleeding, have been well described in athletes; particularly those involved in exercise that is of high impact, weight-bearing and of long duration $^{(41)}$, as encountered during BCT. These exercise-induced losses include gastrointestinal bleeding, haemolysis due to repetitive foot strike, haematuria and sweat ${ }^{(4,5)}$.

Physical training may also reduce Fe status through the action of the liver-derived peptide, hepcidin, to inhibit Fe absorption $^{(42,43)}$. Physical training stimulates the production of proinflammatory cytokines, including IL-6, increasing hepcidin expression $^{(44)}$. Hepcidin levels have been shown to peak 3-6 h post-exercise, typically following a peak in IL-6 activity ${ }^{(45-49)}$. It has therefore been proposed that during this transient elevation in hepcidin expression post-exercise, dietary Fe absorption and Fe recycling from macrophages may temporarily be reduced ${ }^{(50)}$. Consequently, during periods of heavy training, with regular and successive inflammatory responses, consistent with the nature of $\mathrm{BCT}$, this reduction in $\mathrm{Fe}$ absorption and recycling during hepcidin expression may further compromise the individual's Fe status. Fe deficiency will likely occur if dietary Fe intake is not sufficiently increased to match the Fe demand, Fe losses or blockage of Fe absorption.

Duration is a strength of the present study. Fe status indicators were measured 15 weeks apart, while no previous studies in military women undergoing training have investigated $\mathrm{Fe}$ status beyond 10 weeks. The findings therefore reflect changes in Fe status that are much closer to the 120 - $d$ lifespan of erythrocytes ${ }^{51)}$. A further strength is the measurement of the inflammatory biomarker, CRP, and exclusion of participants who had a CRP $>10 \mathrm{mg} / \mathrm{l}$ at either baseline or the end ${ }^{(38)}$. Of the 108 participants available for this study, 106 volunteered to participate. The results therefore accurately reflect the characteristics of female recruits joining the New Zealand Army during the study period.

A limitation of this study is that the follow-up physical performance tests were not conducted at the same time as the Fe status biomarkers, creating challenges in interpreting and comparing the results. The volunteers who presented with Fe deficiency at baseline were provided Fe supplementation and excluded from further investigation. This ruled out the ability to investigate whether Fe status indicators in the clinically deficient range at baseline were associated with completion of BCT. The study was also limited by no analysis of the contribution of dietary intake or blood loss (e.g. menstrual bleeding) towards understanding the cause of diminished Fe status during BCT. However, all food is provided to recruits during BCT and a previous assessment of New Zealand Army male and female recruits' nutrition intake in garrison (NM Martin and RJM Smeele, unpublished results) indicated that recruits consume on average $16000 \mathrm{~kJ}, 150 \mathrm{~g}$ protein and $22 \mathrm{mg} \mathrm{Fe} / \mathrm{d}$, suggesting adequate intake.

Future studies should attempt to investigate the dietary intake and menstrual cycle of female recruits in conjunction with $\mathrm{Fe}$ status indicators, including inflammatory biomarkers in an effort to identify the mechanism by which Fe status declines during BCT. Fe status in military women should be monitored after BCT and throughout advanced training in order to understand the impact on $\mathrm{Hb}$ beyond $120 \mathrm{~d}$ and any further consequences for physical performance. Establishing a consensus amongst clinicians and researchers for Fe status indicators and their cut-off values that infer a negative effect on aerobic performance should 
be prioritised. In physically active premenopausal women, including military women, consideration should be given to expected declines in Fe status during intensive training periods.

In conclusion, $\mathrm{Fe}$ status indicators (excluding $\mathrm{Hb}$ ) were diminished during BCT, and poor Fe status was associated with slower run times, indicating impaired aerobic fitness. In contrast, reduced Fe status did not appear to affect press-ups, a predominantly anaerobic-based test. These findings suggest that tissue-Fe status in particular is reduced in female recruits during BCT and may impair aerobic fitness, which has been strongly associated with the risk of injuries in military recruits and is fundamental to carrying out mission critical tasks. Maintaining or improving Fe status may help optimise the physical performance of military women. Initiatives for future consideration include $\mathrm{Fe}$ screening at appropriate times throughout a military woman's career, Fe supplementation as appropriate, nutrition education regarding dietary intake and timing of bioavailable $\mathrm{Fe}$, and ensuring that military dining halls provide foods that enhance Fe absorption.

\section{Acknowledgements}

The authors would like to thank the female recruits who volunteered to participate in the present study; the Command staff and instructors at the Army Depot; and the medical staff at the Waiouru Defence Health Centre, Waiouru Military Camp. The authors would like to acknowledge the following New Zealand Army Medical Officers for their professional support during the data collection, Drs Ali Riniker, Malcolm Joblin, Katia Hayes and Kate Stanbridge. The authors would also like to thank Catherine Rollo and Drs Peter Elder and John Lewis from Canterbury Health Laboratories and Darrell Monk and Jane Kerridge from Medlab Whanganui for their support in the writing of the methodology.

The present study was funded by the New Zealand Army, with a financial contribution towards the conduct of the study from the School of Sport, Exercise and Nutrition, Massey University.

The authors' contributions are as follows: N. M. M. was the principal investigator and wrote the manuscript; N. M. M., K. L. B., C. A. C., P. R. v. H. and J. P. M. contributed to the study design; N. M. M., R. J. M. S. and O. A. R. M. contributed to the conduct of the study, including participant briefings and data collection; N. M. M. and K. L. B. completed the data analyses; and N. M. M., K. L. B., C. A. C., P. R. v. H. and J. P. M. contributed to the interpretation of the findings. All authors read, revised and approved the final version of the manuscript.

The authors have no financial or personal conflicts of interest to declare.

\section{References}

1. McClung JP \& Murray-Kolb LE (2013) Iron nutrition and premenopausal women: effects of poor iron status on physical and neuropsychological performance. Annu Rev Nutr 33, 271-288.

2. Heath AL, Skeaff CM, Williams S, et al. (2001) The role of blood loss and diet in the aetiology of mild iron deficiency in premenopausal adult New Zealand women. Public Health Nutr 4, 197-206.
3. Harvey LJ, Armah CN, Dainty JR, et al. (2005) Impact of menstrual blood loss and diet on iron deficiency among women in the UK. BrJ Nutr 94, 557-564.

4. Peeling P, Dawson B, Goodman C, et al. (2008) Athletic induced iron deficiency: new insights into the role of inflammation, cytokines and hormones. Eur J Appl Physiol 103, 381-391.

5. Shephard RJ (2016) Exercise proteinuria and hematuria: current knowledge and future directions. J Sports Med Phys Fitness 56, 1060-1076.

6. DellaValle DM \& Haas JD (2011) Impact of iron depletion without anemia on performance in trained endurance athletes at the beginning of a training season: a study of female collegiate rowers. Int J Sport Nutr Exerc Metab 21, 501-506.

7. Dubnov G \& Constantini NW (2004) Prevalence of iron depletion and anemia in top-level basketball players. Int $J$ Sport Nutr Exerc Metab 14, 30-37.

8. Landahl G, Adolfsson P, Borjesson M, et al. (2005) Iron deficiency and anemia: a common problem in female elite soccer players. Int J Sport Nutr Exerc Metab 15, 689-694.

9. Parks RB, Hetzel SJ \& Brooks MA (2017) Iron deficiency and anemia among collegiate athletes: a retrospective chart review. Med Sci Sports Exerc 49, 1711-1715.

10. Sinclair LM \& Hinton PS (2005) Prevalence of iron deficiency with and without anemia in recreationally active men and women. J Am Diet Assoc 105, 975-978.

11. McClung JP, Marchitelli LJ, Friedl KE, et al. (2006) Prevalence of iron deficiency and iron deficiency anemia among three populations of female military personnel in the US Army. J Am Coll Nutr 25, 64-69.

12. McClung JP, Karl JP, Cable SJ, et al. (2009) Randomized, double-blind, placebo-controlled trial of iron supplementation in female soldiers during military training: effects on iron status, physical performance, and mood. Am J Clin Nutr $\mathbf{9 0}$, 124-131.

13. Celsing F, Blomstrand E, Werner B, et al. (1986) Effects of iron deficiency on endurance and muscle enzyme activity in man. Med Sci Sports Exerc 18, 156-161.

14. Gardner GW, Edgerton VR, Senewiratne B, et al. (1977) Physical work capacity and metabolic stress in subjects with iron deficiency anemia. Am J Clin Nutr 30, 910-917.

15. Tufts DA, Haas JD, Beard JL, et al. (1985) Distribution of hemoglobin and functional consequences of anemia in adult males at high altitude. Am J Clin Nutr 42, 1-11.

16. Brownlie T, Utermohlen V, Hinton PS, et al. (2002) Marginal iron deficiency without anemia impairs aerobic adaptation among previously untrained women. Am J Clin Nutr $\mathbf{7 5}$, 734-742.

17. Brownlie T, Utermohlen V, Hinton PS, et al. (2004) Tissue iron deficiency without anemia impairs adaptation in endurance capacity after aerobic training in previously untrained women. Am J Clin Nutr 79, 437-443.

18. McClung JP, Karl JP, Cable SJ, et al. (2009) Longitudinal decrements in iron status during military training in female soldiers. Br J Nutr 102, 605-609.

19. Jones BH, Hauret KG, Dye SK, et al. (2017) Impact of physical fitness and body composition on injury risk among active young adults: a study of Army trainees. J Sci Med Sport 20, Suppl. 4, S17-S22.

20. Karl JP, Lieberman HR, Cable SJ, et al. (2010) Randomized, double-blind, placebo-controlled trial of an iron-fortified food product in female soldiers during military training: relations between iron status, serum hepcidin, and inflammation. $\mathrm{Am} \mathrm{J}$ Clin Nutr 92, 93-100.

21. New Zealand Defence Force (2016) More Military Women Programme. Wellington: New Zealand Defence Force. 
22. Anderson GJ \& Frazer DM (2017) Current understanding of iron homeostasis. Am J Clin Nutr 106, 1559S-1566S.

23. Department of Health and Ageing and Ministry of Health (2006) Nutrient Reference Values for Australia and New Zealand: Including Recommended Dietary Intakes. Canberra: Commonwealth of Australia.

24. University of Otago and Ministry of Health (2011) Methodology Report for the 2008/09 New Zealand Adult Nutrition Survey. Wellington: Ministry of Health.

25. Stewart A \& Marfell-Jones M (2011) International Standards for Anthropometric Assessment. Lower Hutt: International Society for the Advancement of Kinanthropometry.

26. Field AP (2009) Discovering Statistics Using SPSS (and Sex and Drugs and Rock ' $n$ ' Roll), 4th ed. Los Angeles, CA: SAGE Publications Ltd.

27. Hauschild VD, DeGroot DW, Hall SM, et al. (2017) Fitness tests and occupational tasks of military interest: a systematic review of correlations. Occup Environ Med 74, 144-153.

28. Ashenden MJ, Martin DT, Dobson GP, et al. (1998) Serum ferritin and anemia in trained female athletes. Int J Sport Nutr $\mathbf{8}, 223-229$.

29. Hinton PS, Giordano C, Brownlie T, et al. (2000) Iron supplementation improves endurance after training in irondepleted, nonanemic women. J Appl Physiol (1985) 88, 1103-1111.

30. Blacker SD, Wilkinson DM, Bilzon JL, et al. (2008) Risk factors for training injuries among British Army recruits. Mil Med 173, 278-286.

31. Hall LJ (2017) Relationship between 1.5-mile run time, injury risk and training outcome in British Army recruits. J R Army Med Corps 163, 376-382.

32. Jones BH \& Hauschild VD (2015) Physical training, fitness, and injuries: lessons learned from military studies. J Strength Cond Res 29, Suppl. 11, S57-S64.

33. Nindl BC, Jones BH, Van Arsdale SJ, et al. (2016) Operational physical performance and fitness in military women: physiological, musculoskeletal injury, and optimized physical training considerations for successfully integrating women into combat-centric military occupations. Mil Med 181, 50-62.

34. Lisman PJ, de la Motte SJ, Gribbin TC, et al. (2017) A systematic review of the association between physical fitness and musculoskeletal injury risk: part 1-cardiorespiratory endurance. J Strength Cond Res 31, 1744-1757.

35. University of Otago and Ministry of Health (2011) A Focus on Nutrition: Key Findings of the 2008/09 New Zealand Adult Nutrition Survey. Wellington: Ministry of Health.
36. Dubnov G, Foldes AJ, Mann G, et al. (2006) High prevalence of iron deficiency and anemia in female military recruits. $\mathrm{Mil}$ Med 171, 866-869.

37. Israeli E, Merkel D, Constantini N, et al. (2008) Iron deficiency and the role of nutrition among female military recruits. Med Sci Sports Exerc 40, S685-S690.

38. Zimmermann MB \& Hurrell RF (2007) Nutritional iron deficiency. Lancet 370, 511-520.

39. World Health Organization (2017) Nutritional Anaemias: Tools for Effective Prevention and Control. Geneva: World Health Organization.

40. Beard J \& Tobin B (2000) Iron status and exercise. Am J Clin Nutr 72, 594s-597s.

41. Telford RD, Sly GJ, Hahn AG, et al. (2003) Footstrike is the major cause of hemolysis during running. J Appl Physiol (1985) 94, 38-42.

42. Park CH, Valore EV, Waring AJ, et al. (2001) Hepcidin, a urinary antimicrobial peptide synthesized in the liver. $J$ Biol Chem 276, 7806-7810

43. Nemeth E, Tuttle MS, Powelson J, et al. (2004) Hepcidin regulates cellular iron efflux by binding to ferroportin and inducing its internalization. Science 306, 2090-2093.

44. Roecker L, Meier-Buttermilch R, Brechtel L, et al. (2005) Ironregulatory protein hepcidin is increased in female athletes after a marathon. Eur J Appl Physiol 95, 569-571.

45. Peeling P, Dawson B, Goodman C, et al. (2009) Cumulative effects of consecutive running sessions on hemolysis, inflammation and hepcidin activity. Eur J Appl Physiol 106, 51-59.

46. Peeling P, Sim M, Badenhorst CE, et al. (2014) Iron status and the acute post-exercise hepcidin response in athletes. PLOS ONE 9, e93002.

47. Sim M, Dawson B, Landers G, et al. (2012) The effects of carbohydrate ingestion during endurance running on postexercise inflammation and hepcidin levels. Eur J Appl Physiol 112, 1889-1898.

48. Newlin MK, Williams S, McNamara T, et al. (2012) The effects of acute exercise bouts on hepcidin in women. Int J Sport Nutr Exerc Metab 22, 79-88.

49. Peeling P, McKay AKA, Pyne DB, et al. (2017) Factors influencing the post-exercise hepcidin-25 response in elite athletes. Eur J Appl Physiol 117, 1233-1239.

50. Peeling P (2010) Exercise as a mediator of hepcidin activity in athletes. Eur J Appl Physiol 110, 877-883.

51. Dallman PR (1986) Biochemical basis for the manifestations of iron deficiency. Annu Rev Nutr 6, 13-40. 